\title{
Isolation and characterization of aerobic actinomycetes with probiotic properties in Nile tilapia
}

\author{
Jirayut Euanorasetr ${ }^{1,2^{*}}$, Varissara Chotboonprasit ${ }^{1,2}$, Wacharaporn Ngoennamchok ${ }^{1,2}$, Sutassa Thongprathueang ${ }^{1,2}$, Archiraya \\ Promprateep $^{1,2}$, Suppakit Taweesaga ${ }^{1,2}$, Pongsan Chatsangjaroen ${ }^{1,2}$, Bungonsiri Intra ${ }^{3,4}$ \\ ${ }^{1}$ Department of Microbiology, Faculty of Science, King Mongkut's University of Technology Thonburi, Khet Thung Khru, Bangkok 10140, Thailand \\ ${ }^{2}$ Laboratory of biotechnological research for energy and bioactive compounds, Department of Microbiology, Faculty of Science, King Mongkut's University \\ of Technology Thonburi, Khet Thung Khru, Bangkok 10140, Thailand \\ ${ }^{3}$ Mahidol University-Osaka University: Collaborative Research Center for Bioscience and Biotechnology (MU-OU: CRC), Faculty of Science, Mahidol \\ University, Bangkok 10400, Thailand \\ ${ }^{4}$ Department of Biotechnology, Faculty of Science, Mahidol University, Bangkok 10400, Thailand
}

\begin{tabular}{l}
\hline ARTICLE INFO \\
\hline Received on: $20 / 04 / 2020$ \\
Accepted on: $23 / 06 / 2020$ \\
Available online: $05 / 09 / 2020$ \\
\\
\hline Key words: \\
Actinomycetes, antibacterial \\
activity, probiotics, bacterial \\
pathogens, Nile tilapia.
\end{tabular}

\section{INTRODUCTION}

Nile tilapia or Pla Nin (Oreochromis niloticus) is a freshwater fish with great economic importance in Thailand and represents the highest quantity of freshwater aquaculture at two hundred thousand tons and a cost of nearly 12 billion baht since 2012 until 2016 (Ministry of Agriculture and Cooperatives (Thailand), 2016). Moreover, they are also one of the most productive international freshwater food fish at four million tons, with eight billion US dollars in 2016 (Wang and Lu, 2016). Due to the continual increase in global food demand, several countries,

\footnotetext{
${ }^{*}$ Corresponding Author

Jirayut Euanorasetr, Department of Microbiology, Faculty of Science, King Mongkut's University of Technology Thonburi, Bangkok, Thailand. E-mail: jirayut.eua@kmutt.ac.th
}

including Thailand, have tried to increase aquaculture production. Therefore, intensive farming has been adopted, and subsequently, bacterial or viral infections have been reported in Thailand and other countries (Dong et al., 2015; Kannika et al., 2017; Win et al., 2017) that are caused by several bacterial pathogens, including Streptococcus agalactiae, Vibrio cholera, Aeromonas veronii, and Edwardsiella ictaluri. From previous reports, disease outbreaks in the floating cage of cultured Nile tilapia were detected in Mekong river, and the example of observed symptoms caused by $A$. veronii was hemorrhages in the internal organs, e.g., fins and liver (Dong et al., 2015).

Nowadays, the conventional treatment for bacterial infection in Nile tilapia is to apply antibiotics. However, antibiotic residue and antibiotic-resistant bacteria in Nile Tilapia were also observed in several countries, like Ghana (Donkor et al., 2018) and China (Zhang et al., 2018), which lead to rejection due to the 
food safety regulations. Organized animal husbandry practices and the use of antibiotic alternatives, such as vaccination, probiotics, phage therapy, and essential oils, are recommended to reduce the number of antimicrobial residues in aquaculture and consequently in food safety effects (Okocha et al., 2018). Probiotics are defined as active microorganisms providing positive health effects to the hosts (de Vrese and Schrezenmeir, 2008). The proposed mechanisms of beneficial properties of probiotics comprise the reduction of pathogenic microorganisms, the promotion of the growth rate of the host, and improving the water quality (Babu et al., 2018; Das et al., 2010). The application of probiotics in aquaculture was initially evaluated by several research groups to ensure host safety and effectiveness against infectious diseases (Chen et al., 2019; Das et al., 2008; Tan et al., 2016). The criteria concerned with probiotic strains included the ability to tolerate the environment within the gastrointestinal (GI) tract of the host, the ability to adhere to the host epithelial cells, antibacterial activity to the pathogenic bacteria, and also the ability to degrade the complex biomolecules for better nutrient absorption in the host (de Vrese and Schrezenmeir, 2008; Markowiak and Ślizewska, 2018).

Actinomycetes are mostly Gram-positive, filamentous bacteria in the phylum Actinobacteria, with high $\mathrm{G}+\mathrm{C}$ DNA content in their genomes (Barka et al., 2016). They are ubiquitous with a wide range of natural habitats, soil, sediment, mangrove, and marine, and are well known as producers of secondary metabolites, which constitutes about $30 \%$ of the total microbial metabolites. Until now, more than 10,000 bioactive metabolites had been isolated from actinomycetes (Bérdy, 2012). Especially, many commercial antibiotics are derived from the genus Streptomyces, e.g., chloramphenicol and streptomycin, and from S. venezuelae and S. griseus, respectively (Kieser et al., 2000). Not only are actinomycetes the source for bioactive compounds, but they also include the important industrial enzymes, e.g., lignocellulolytic enzymes (Kumar et al., 2016; Saini et al., 2015; Shivlata and Satyanarayana, 2015).

Several pieces of research focus on searching for new bioactive compounds or new activity in Thai actinomycetes (Euanorasetr et al., 2015; Intra et al., 2011; Ser et al., 2017). However, no recent research has focused on the actinomycete strains with antibacterial activity against bacterial pathogens in Nile tilapia. Several pieces of research indicate that actinomycetes are promising sources that can be used as probiotics for aquaculture (Das et al., 2008; Tan et al., 2016). Therefore, in this study, the isolation of actinomycete strains from rhizosphere soil and their antibacterial activity was initially evaluated against four bacterial pathogens (S. agalactiae 2809, A. veronii 1930, Aeromonas jandaei 1929, and Edwardsiella ictaluri 2234) in Nile tilapia and the potent strains were also identified by $16 \mathrm{~S}$ ribosomal ribonucleic acid (rRNA) gene analysis. Moreover, the acid tolerance and bile salt tolerance tests were also investigated to suggest the viability in the GI tract of the fish.

\section{MATERIALS AND METHODS}

\section{Tested bacteria}

Streptococcus agalactiae 2809, A. veronii 1930, and A. jandaei 1929 were grown on a nutrient agar (1\% beef extract, $1 \%$ peptone, $0.5 \%$ sodium chloride, and $1.5 \%$ agar) for 2 days at room temperature, except $E$. ictaluri 2234 was grown at $30^{\circ} \mathrm{C}$ for 2 days. Tested bacteria were kindly provided by Associate Professor Triwit Rattanarojpong, from the Department of Microbiology, Faculty of Science, King Mongkut's University of Technology Thonburi, Thailand, and Dr. Saengchan Senapin, from the Fish Health Platform, Center of Excellence for Shrimp Molecular Biology and Biotechnology (Centex Shrimp), Faculty of Science, Mahidol University, Bangkok, Thailand.

\section{Collection of soil samples and soil analysis}

Soils were collected around the plant root at a depth of $10-15 \mathrm{~cm}$ from the surface using the procedure from a previous research (Intra et al., 2011). There were 11 soil samples from three provinces: Chanthaburi (GPS $12^{\circ} 35^{\prime} 49.5^{\prime \prime} \mathrm{N}$

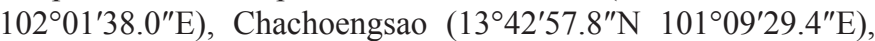
and Nan $\left(18^{\circ} 47^{\prime} 53^{\prime \prime} \mathrm{N} 100^{\circ} 32^{\prime} 34^{\prime \prime} \mathrm{E}\right)$. The soil $\mathrm{pH}$ was evaluated by adding $1 \mathrm{~g}$ of soil sample to $5 \mathrm{~mL}$ of distilled water, mixed well until homogenous, and kept for 60 minutes. Finally, the $\mathrm{pH}$ of supernatants was measured with a $\mathrm{pH}$ meter (Hendershot et al., 2008). Gravimetric soil water content was determined by oven drying at $110^{\circ} \mathrm{C}$ for 2 hours and was calculated by the previous procedure (Standards Association of Australia, 1977).

\section{Isolation of actinomycetes and their characteristics}

The soil samples were air-dried for 1 week. After that, the samples were divided into two conditions: non-heat and heat. The heat condition was $100^{\circ} \mathrm{C}$ for 1 hour in the oven. One gram of soil sample was dissolved in $0.85 \%$ normal saline solution and serially diluted to $10^{-4}$. One hundred $\mu 1$ aliquots was spread on two isolation media: starch casein agar [starch casein agar (SCA); 1\% starch, $0.03 \%$ casein, $0.2 \%$ potassium nitrate, $0.005 \%$ magnesium sulfate, $0.2 \%$ dipotassium hydrogen phosphate, $0.2 \%$ sodium chloride, $0.003 \%$ calcium carbonate, $0.001 \%$ Iron II sulfate, and $1.8 \%$ agar] and water proline agar ( $1 \%$ proline and $1.2 \%$ agar), with nalidixic acid and cycloheximide as the final concentrations of 50 and $25 \mu \mathrm{g} / \mathrm{ml}$, respectively, at room temperature for 4-6 weeks. The total number of actinomycete-like colonies (with leathery, powdery, or butyrous characteristic) was counted as average on two replicating dilution plates. Actinomycete-like colonies were picked and purified in the International Streptomyces Project 2 (ISP2; $0.4 \%$ yeast extract, $1 \%$ malt extract, $0.4 \%$ glucose, and $2 \%$ agar) media. The actinomycete morphology was examined on ISP2 agar using a slide culture technique with a bright field light microscope (Kieser et al., 2000; Shirling and Gottlieb, 1966).

\section{Antibacterial activity of actinomycetes}

The actinomycete strains were grown in 301 production agar $(2.4 \%$ starch, $0.1 \%$ glucose, $0.3 \%$ peptone, $0.3 \%$ meat extract, $0.5 \%$ yeast extract, $0.4 \%$ calcium carbonate, and $1.5 \%$ agar) (Euanorasetr et al., 2010) by streaking at the center of the plate for 7 days. The tested bacteria were perpendicular, cross-streaked to the line of actinomycetes, and the plates were incubated at room temperature for $48 \mathrm{~h}$ (Balouiri et al., 2016). The inhibition zones were observed and recorded in millimeters compared to that of the control plate (without actinomycetes).

\section{$16 \mathrm{~S}$ rRNA gene amplification and phylogenetic tree analysis}

The genomic DNA of actinomycetes was extracted by freeze-thawing and boiling methods (Euanorasetr et al., 2010), while the fragment of partial 16S rRNA gene was amplified by 
polymerase chain reaction (PCR) using the primers $11 \mathrm{~F}$ and 925R (Tajima et al., 2001), with the following conditions: initial denaturation at $95^{\circ} \mathrm{C}$ for 2 minutes, 30 cycles of denaturation at $95^{\circ} \mathrm{C}$ for 30 seconds, annealing at $52^{\circ} \mathrm{C}$ for 30 seconds, extension at $72^{\circ} \mathrm{C}$ for 1 minute, and a final extension at $72^{\circ} \mathrm{C}$ for 3 minutes. The PCR products were confirmed by agarose gel electrophoresis and further purified by AccuPrep PCR Purification Kit (Bioneer, Korea). The purified PCR products were sequenced by the U2Bio Company, Thailand. The partial $16 \mathrm{~S}$ rRNA sequences $(\approx 900 \mathrm{bp})$ were analyzed with EzBioCloud (https://www.ezbiocloud.net/) (Yoon et al., 2017) and were updated on the National Center for Biotechnology Information (NCBI) database with the accession number MH470491-MH470510. After that, partial 16S rRNA gene sequences from isolates were aligned with multiple available sequences of actinomycete type strains from the NCBI database by using the MUSCLE program (Edgar, 2004), while the $16 \mathrm{~S}$ sequence of Bacillus subtilis DSM $10^{\mathrm{T}}$ (AJ276351) was used as the out group. The phylogenetic relationship was inferred by the neighbor-joining method (Saitou and Masatoshi, 1987) using the MEGA version 7.0.26 (Kumar et al., 2016).

\section{Acidity and bile salt tolerance test}

Five milliliters of ISP 2 broth with $\mathrm{pH}$ ranges from 2 to 7 or $0.3 \%$ bile salt was prepared by adding $0.1 \mathrm{M} \mathrm{HCl}$ or bile salt (Himedia, India) to the ISP2 broth before sterilization with an autoclave. From the five strains with consistent antibacterial activity (YNW004, SHS004, LNW002, ZNW001, and TNW007), only one loop of each actinomycete strain was inoculated to the adjusted $\mathrm{pH}$ or bile salt-containing media. After incubation in the incubator shaker at room temperature with $200 \mathrm{rpm}$ for 2 hours, one hundred microliters of the culture broth was spread on the
ISP2 agar and incubated at room temperature for 7 days. The level of the tolerance was evaluated by counting the observed actinomycete colonies: 1-100 colonies represented +, 101-200 colonies represented ++ , and more than 200 colonies represented +++ , while none of the colony represented -.

\section{RESULTS AND DISCUSSION}

\section{Soil analysis}

Eleven soil samples were collected from three provinces: five samples from Chanthaburi [Longkong (Aglaia dookkoo), lemongrass (Cymbopogon citratus), fingerroot (Boesenbergia rotunda), salak (Salacca zalacca), and durian (Durio zibethinus)]; three samples from Chachoengsao [Crudia chrysantha, devil tree (Alstonia scholaris), Bruguiear sexangula]; and three samples from Nan [star apple (Chrysophyllum caimito), Ormosia (Afzelia xylocarpa) and longan (Dimocarpus longan)]. The soil $\mathrm{pH}$ was in the range of 3.58-6.71 which was quite acidic, and the percentage of water in the soil was in the range of $2.60-8.26$, as summarized in Table 1.

\section{Amount of actinomycete and isolation}

The actinomycete-like colonies on isolation plates were observed to have leathery or powdery characteristics according to the general characteristics of the Actinobacteria (Barka et al., 2016). The abundance of soil actinomycetes in each isolating condition is shown in Supplementary Figure 1. The comparison of four isolating conditions revealed that non-heat treatment with SCA gave the highest amount of actinomycetes at $6 \log$ colony forming unit $(\mathrm{CFU}) / \mathrm{g}$, whereas heat treatment with SCA gave the lowest amount at $3.5 \log \mathrm{CFU} / \mathrm{g}$. From Table 1, the average amount of the observed actinomycetes on heat treatment (3.08

Table 1. Detailed information on each soil sample with the amount of actinomycetes isolation.

\begin{tabular}{|c|c|c|c|c|c|c|c|c|c|c|c|}
\hline \multirow{3}{*}{ Rhizosphere } & \multirow{3}{*}{ Geographical origin } & \multirow{3}{*}{ pH } & \multirow{3}{*}{$\begin{array}{c}\% \text { Water in } \\
\text { soil }\end{array}$} & \multicolumn{4}{|c|}{ Starch casein agar (SCA) } & \multicolumn{4}{|c|}{ WP (Water proline agar) } \\
\hline & & & & \multicolumn{2}{|c|}{ Non heat } & \multicolumn{2}{|c|}{ Heat } & \multicolumn{2}{|c|}{ Non heat } & \multicolumn{2}{|c|}{ Heat } \\
\hline & & & & CFU/g soil & No. of isolate & $\mathrm{CFU} / \mathrm{g}$ soil & No. of isolate & CFU/g soil & No. of isolate & CFU/g soil & No. of isolate \\
\hline Longkong & $\begin{array}{l}12^{\circ} 35^{\prime} 49.5^{\prime \prime} \mathrm{N} \\
102^{\circ} 01^{\prime} 38.0^{\prime \prime} \mathrm{E}\end{array}$ & 4.99 & 3.53 & $1.31 \times 10^{5}$ & 2 & $2.41 \times 10^{3}$ & 2 & $2.28 \times 10^{5}$ & 8 & $2.45 \times 10^{4}$ & 7 \\
\hline Lemon grass & $\begin{array}{l}12^{\circ} 35^{\prime} 49.5^{\prime \prime} \mathrm{N} \\
102^{\circ} 01^{\prime} 38.0^{\prime \prime} \mathrm{E}\end{array}$ & 5.90 & 5.32 & $6.55 \times 10^{4}$ & 1 & $3.02 \times 10^{3}$ & 4 & $1.04 \times 10^{6}$ & 5 & $2.02 \times 10^{5}$ & 7 \\
\hline Fingerroot & $\begin{array}{l}12^{\circ} 35^{\prime} 49.5^{\prime \prime} \mathrm{N} \\
102^{\circ} 01^{\prime} 38.0^{\prime \prime} \mathrm{E}\end{array}$ & 5.28 & 8.26 & $1.83 \times 10^{5}$ & 4 & $3.44 \times 10^{3}$ & 4 & $3.49 \times 10^{5}$ & 3 & $6.00 \times 10^{4}$ & 5 \\
\hline Salak & $\begin{array}{l}12^{\circ} 35^{\prime} 49.5^{\prime \prime} \mathrm{N} \\
102^{\circ} 01^{\prime} 38.0^{\prime \prime} \mathrm{E}\end{array}$ & 4.32 & 4.49 & $3.75 \times 10^{4}$ & 0 & $3.03 \times 10^{3}$ & 0 & $1.48 \times 10^{5}$ & 6 & $1.98 \times 10^{5}$ & 3 \\
\hline Durian & $\begin{array}{l}12^{\circ} 35^{\prime} 49.5^{\prime \prime} \mathrm{N} \\
102^{\circ} 01^{\prime} 38.0^{\prime \prime} \mathrm{E}\end{array}$ & 5.40 & 4.73 & $1.74 \times 10^{5}$ & 1 & $1.05 \times 10^{3}$ & 0 & $4.64 \times 10^{5}$ & 2 & $2.25 \times 10^{4}$ & 4 \\
\hline Star apple & $\begin{array}{l}18^{\circ} 47^{\prime} 53^{\prime \prime} \mathrm{N} \\
100^{\circ} 32^{\prime} 34^{\prime \prime} \mathrm{E}\end{array}$ & 5.37 & 4.24 & $1.52 \times 10^{4}$ & 3 & $3.95 \times 10^{3}$ & 4 & $4.11 \times 10^{5}$ & 5 & $7.01 \times 10^{3}$ & 0 \\
\hline Ormosia & $\begin{array}{l}18^{\circ} 47^{\prime} 53^{\prime \prime} \mathrm{N} \\
100^{\circ} 32^{\prime} 34^{\prime \prime} \mathrm{E}\end{array}$ & 6.71 & 5.12 & $7.2 \times 10^{6}$ & 13 & $2.47 \times 10^{3}$ & 0 & $2.88 \times 10^{6}$ & 4 & $9.75 \times 10^{4}$ & 4 \\
\hline Longan & $\begin{array}{l}18^{\circ} 47^{\prime} 53^{\prime \prime} \mathrm{N} \\
100^{\circ} 32^{\prime} 34^{\prime \prime} \mathrm{E}\end{array}$ & 4.97 & 3.63 & $3.20 \times 10^{4}$ & 3 & $3.66 \times 10^{3}$ & 0 & $1.66 \times 10^{5}$ & 5 & $4.35 \times 10^{3}$ & 3 \\
\hline C. chrysantha & $\begin{array}{l}13^{\circ} 42^{\prime} 57.8^{\prime \prime} \mathrm{N} \\
101^{\circ} 09^{\prime} 29.4^{\prime \prime} \mathrm{E}\end{array}$ & 4.02 & 2.60 & $4.05 \times 10^{4}$ & 2 & $3.25 \times 10^{3}$ & 0 & $6.98 \times 10^{5}$ & 7 & $3.30 \times 10^{3}$ & 0 \\
\hline Devil tree & $\begin{array}{l}13^{\circ} 42^{\prime} 57.8^{\prime \prime} \mathrm{N} \\
101^{\circ} 09^{\prime} 29.4^{\prime \prime} \mathrm{E}\end{array}$ & 3.58 & 3.10 & $1.55 \times 10^{5}$ & 1 & $3.25 \times 10^{3}$ & 0 & $3.73 \times 10^{4}$ & 3 & $3.25 \times 10^{3}$ & 1 \\
\hline $\begin{array}{l}\text { Bruguiera } \\
\text { sexangular }\end{array}$ & $\begin{array}{l}13^{\circ} 42^{\prime} 57.8^{\prime \prime} \mathrm{N} \\
101^{\circ} 09^{\prime} 29.4^{\prime \prime} \mathrm{E}\end{array}$ & 6.02 & 3.14 & $3.30 \times 10^{6}$ & 2 & $3.10 \times 10^{3}$ & 8 & $3.47 \times 10^{5}$ & 11 & $2.21 \times 10^{4}$ & 10 \\
\hline
\end{tabular}


$\left.\times 10^{4} \mathrm{CFU} / \mathrm{g}\right)$ was lower than that of non-heat treatment $(8.23 \times$ $\left.10^{5} \mathrm{CFU} / \mathrm{g}\right)$. In this study, the heat treatment was included in the isolation process in order to increase the chance of discovering rare actinomycetes and exclude other bacteria and fungi. Heat resulted in reducing the amount of fast-growing or filamentous bacteria, including streptomycetes (Hayakawa, 2008). The total isolates were lower than the number of actinomycetes in the soil at $10^{4}-10^{8}$ CFU/g from a previous report (Bhatti et al., 2017), which might be explained by the fact that the soil samples were in acidic condition (Table 1) and most soil actinomycetes are mesophilic (Goodfellow and Williams, 1983). From Table 1, 54 and 103 actinomycete strains were isolated from SCA and WP, respectively. Notably, most heat-tolerant actinomycetes (18 isolates) were isolated from soil under Ormosia, while most heat-sensitive actinomycetes (13 isolates) were also isolated from soil under Ormosia.

All isolates were purified in a single colony ISP2 agar and the characteristics of Actinobacteria were examined under the bright field microscope. One of the isolates, strain LNW002, grew well on ISP2 agar with gray aerial mycelium with sporulation. A brown diffusible pigment was also present in the cultures grown on ISP2 medium. Colonies and sporulating mycelia of strain LNW002 are shown in Figure 1A and B. Observation using light microscopy revealed branching vegetative mycelium and aerial hyphae with 10-30 spores in a chain (Fig. 1B). Morphologically, the characteristics of this strain belonged to the genus Streptomyces with the presence of mycelium and a long chain of spores. Streptomycetes are generally characterized as aerobic, Grampositive, non-acid-fast bacteria that form an extensively branched substrate and aerial mycelia. At maturity, the aerial mycelium forms chains of three or more spores (Goodfellow, 2012).

\section{Antibacterial pathogens in Nile tilapia from actinomycetes}

A total of 157 isolated actinomycetes were tested against four bacterial pathogens in Nile tilapia ( $S$. agalactiae 2809, A. veronii 1930, A. jandaei 1929, and E. ictaluri 2234). The results showed that 108 strains $(69 \%)$ showed antibacterial activity against at least one bacterial pathogen. From these active strains, most actinomycetes (98 strains) showed antibacterial

A B

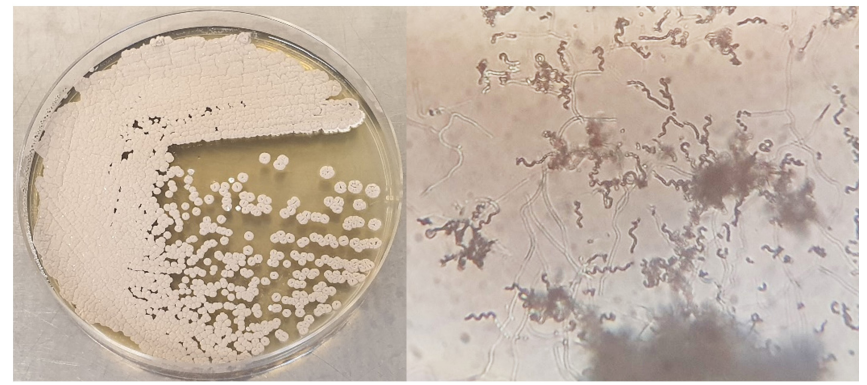

Figure 1. Streptomyces spp. LNW002; The colony morphology of LNW002 grown for 8 days at room temperature on yeast extract-malt extract agar (ISP2). Front side $(\mathrm{A})$ and back side $(\mathrm{B})$. The mycelia $(\times 1,000)$ on ISP2 agar for 8 days at room temperature.

\section{$\log$ CFU/g}

7

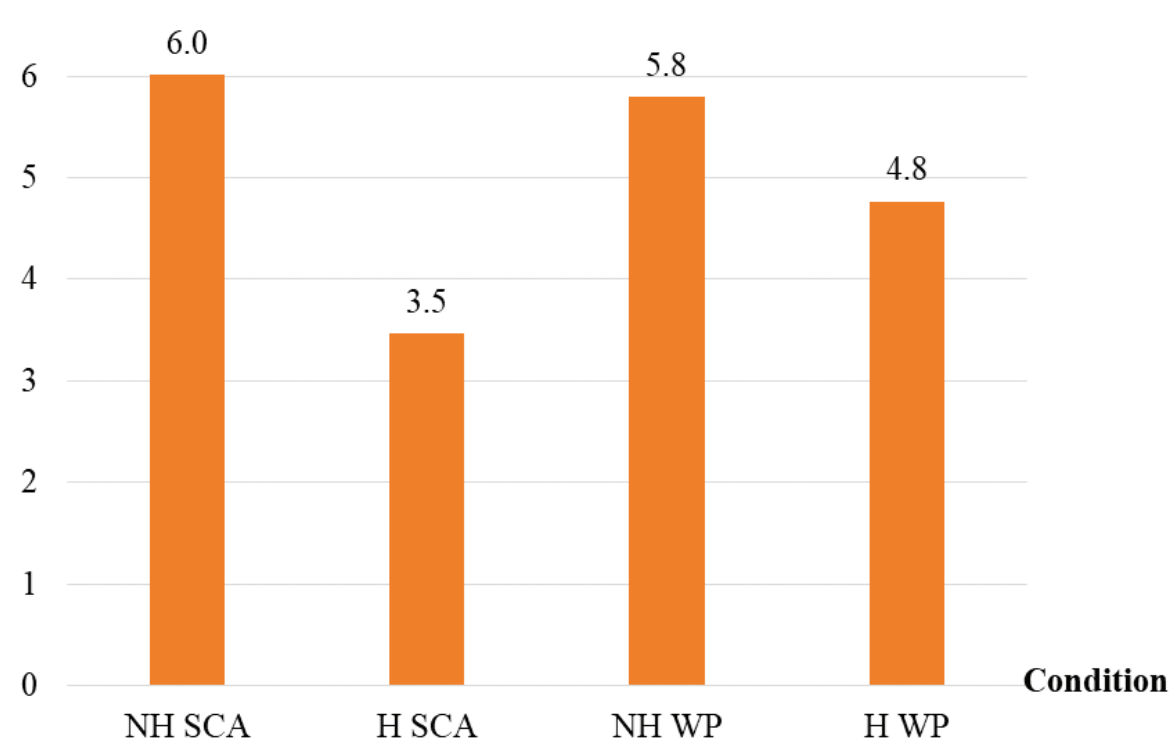

Supplementary Figure 1. Amount of actinomycetes in each condition. NH SCA means non-heat condition with SCA, H SCA means heat condition with SCA, NH WP means non-heat condition with WP, and H WP means heat condition with WP. 
activity against E. ictaluri 2234, while 31,43 , and 35 strains could inhibit A. veronii 1930, A. jandaei 1929, and S. agalactiae 2809, respectively (Supplementary Fig. 2). Some of the inhibition zone sizes were recorded and are shown in Table 2 and Supplementary Figure 3, respectively. Generally, actinomycetes demonstrate antibacterial activity against Gram-positive bacteria more than Gram-negative bacteria (Euanorasetr et al., 2010; Thakur et al., 2007). However, in this study, most active isolates showed antibacterial activity against Gram-negative E. ictaluri. One possible reason was that E. ictaluri was quite sensitive to several classes of antibiotics, such as aminoglycosides and quinolones (Waltman and Shotts, 1986). On the other hand, there was a report of natural E. ictaluri with resistance to streptomycin, oxytetracycline, and trimethoprim in Vietnam (Dung et al., 2008). To our knowledge, this study was the first to report on anti- $E$ ictaluri activity in streptomycetes. Further purification of the bioactive compounds from strains with potent antibacterial activity with all tested bacteria (FNW003, FSH015, WNW026, and KNS006; Table 2) are promising. Moreover, antibiotics in a class of tetracycline (e.g., chlortetracycline, oxytetracycline, and tetracycline), flumequine, and deltamethrin were still allowed to be employed during the early bacterial infection in Nile tilapia in Thailand. Therefore, new bioactive compounds are still essential to treat the bacterial infection in Nile tilapia.

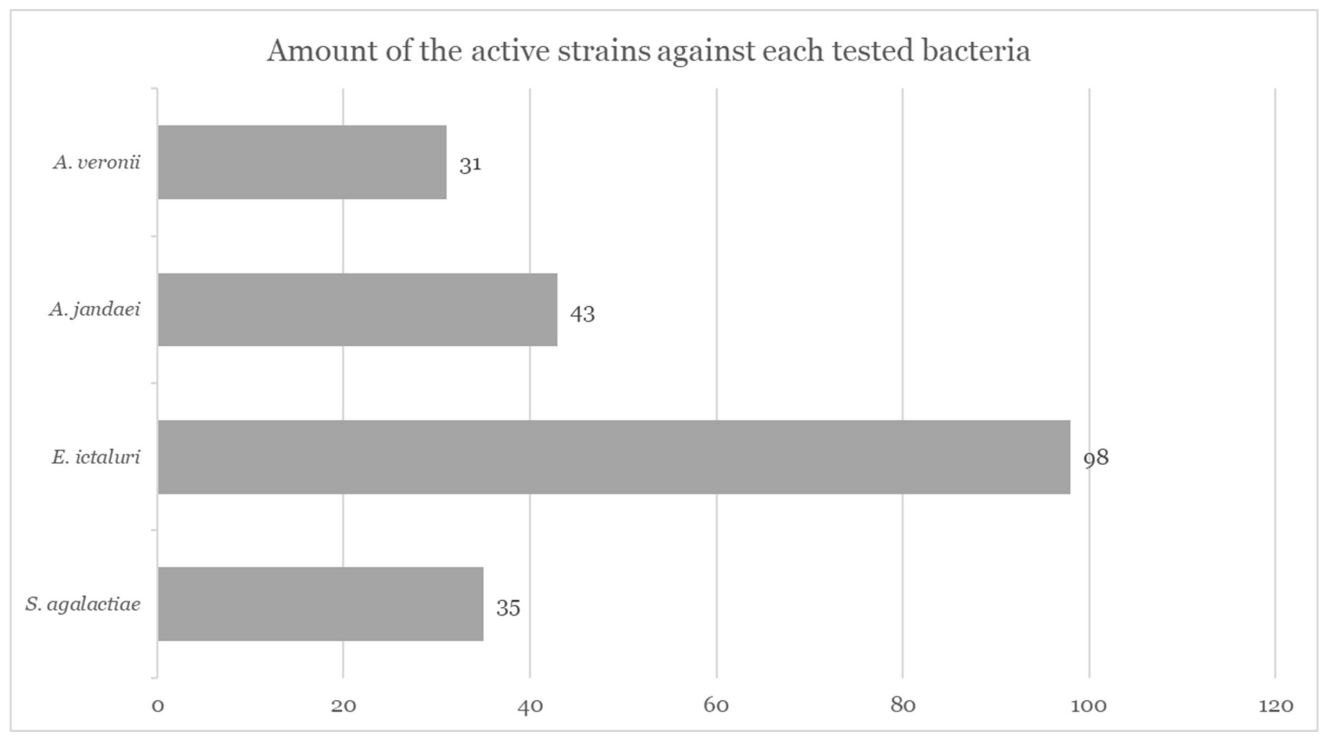

Supplementary Figure 2. Antibacterial activities of isolated actinomycetes against each bacterial pathogen in Nile tilapia.

Table 2. Inhibition zone of twenty actinomycetes isolates and tested bacteria.

\begin{tabular}{|c|c|c|c|c|}
\hline \multirow{2}{*}{ Isolates/tested bacteria } & \multicolumn{4}{|c|}{ Inhibition zone (mm.) } \\
\hline & S. agalactiae 2809 & A. jandaei 1929 & A. veronii 1930 & E. ictaluri 2234 \\
\hline FNW003 & 24 & 29 & 16 & 21 \\
\hline LNW002 & 15 & - & - & 11 \\
\hline DNW003 & - & 8 & 11 & 7 \\
\hline UNW008 & 10 & 7 & - & 5 \\
\hline WNW026 & 9 & 14 & 13 & 18 \\
\hline KNW004 & 5 & - & - & 15 \\
\hline KNW020 & - & - & - & 20 \\
\hline KNW005 & - & - & - & 14 \\
\hline ZNW001 & - & 13 & 8 & 5 \\
\hline YNW004 & - & - & - & 8 \\
\hline TNW007 & - & - & - & 8 \\
\hline KHS006 & - & 14 & 14 & - \\
\hline FHS015 & 19 & 12 & 30 & 20 \\
\hline YNS007 & 3 & 7 & 6 & 9 \\
\hline WHS020 & - & - & - & 14 \\
\hline KNS006 & 12 & 13 & 19 & 20 \\
\hline SNS004 & 4 & 7 & 5 & 15 \\
\hline
\end{tabular}




\section{Molecular identification of actinomycetes with antibacterial activity}

Seventeen strains with strong antibacterial activity against one or all tested bacterial pathogens were chosen to be further identified by partial 16S rRNA gene sequence analysis. The expected PCR product size about $900 \mathrm{bp}$ from $11 \mathrm{~F}$ and $925 \mathrm{R}$ primers was observed (data not shown) and was purified and later sequenced. Results from the analysis by the EzBiocloud database revealed that most of the active strains belonged to the genus Streptomyces with the similarity percentage above $98 \%$, except for strain KNS006, which was identified as Nocardia nova NITE Biological Resource Center (NBRC) $15556^{\mathrm{T}}$ with $100 \%$ similarity (Table 3). Moreover, the phylogenetic tree of $16 \mathrm{~S}$ rRNA sequences derived from the neighbor-joining analysis also supported the relationships between the isolates with other actinomycetes strains (Fig. 2). Because Nocardia sp. KNS006 possessed both antibacterial activity against all tested bacteria (Table 2), and there was no report on the bioactivity from $N$. nova NBRC $15556^{\mathrm{T}}$ yet, but bioactive compounds purification from this strain is promising. Based on the $16 \mathrm{~S}$ rRNA gene sequence analysis and the phylogenetic analysis, most of the active isolates were identified in the genus Streptomyces. Streptomycetes are abundant in the soil (Goodfellow and Williams, 1983) and several studies indicated the possibility to obtain this group of bacteria by using SCA and WP media supplemented with antibiotics (Euanorasetr et al., 2010; Sripreechasak et al., 2017). This fact is in agreement with a previous report that streptomycetes were the prominent sources of bioactive compounds from Actinobacteria (Bérdy, 2012). Strain SNS004 was interesting as the putative new species because of the lower percentage of $16 \mathrm{~S}$ rRNA similarity than $99 \%$. Therefore, further study on physiological and genotypic comparison of this strain with Streptomyces hyaluromycini NBRC $110483^{\mathrm{T}}$ and other
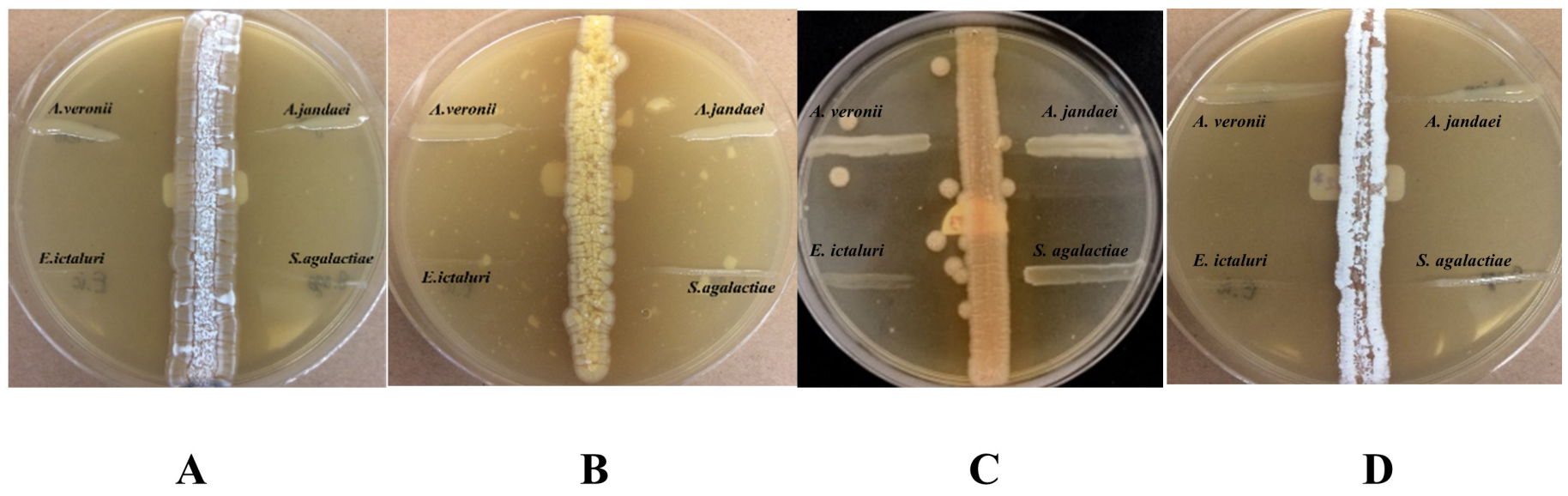

B

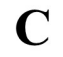

D

Supplementary Figure 3. Examples of inhibiting antibacterial activities of isolated actinomycetes FNW003 (A), WNW026 (B), SNS003 (C), and LNW002 (D) against each bacterial pathogen.

Table 3. Identification of actinomycetes by partial $16 \mathrm{~S}$ rRNA sequence and Ezbiocloud analysis.

\begin{tabular}{|c|c|c|c|}
\hline Strain code & Nearest relatives & Accession number & \% Similarity \\
\hline FNW003 & Streptomyces albaduncus JCM $4715^{\mathrm{T}}$ & AY999757 & 100.00 \\
\hline LNW002 & S. fodineus $\mathrm{TW} 1 \mathrm{~S} 1^{\mathrm{T}}$ & KT820007 & 99.63 \\
\hline DNW003 & Streptomyces lannensis TA4-8 $8^{\mathrm{T}}$ & AB562508 & 100.00 \\
\hline UNW008 & Streptomyces ramulosus NRRL B-2714 ${ }^{\mathrm{T}}$ & DQ026662 & 99.24 \\
\hline WNW026 & Streptomyces phaeoluteigriseus DSM $41896^{\mathrm{T}}$ & МРОH01000466 & 99.50 \\
\hline KNW004 & Streptomyces bungoensis DSM $41781^{\mathrm{T}}$ & KQ948892 & 99.63 \\
\hline KNW020 & Streptomyces coelicoflavus NBRC $15399^{\mathrm{T}}$ & AB184650 & 99.63 \\
\hline KNW005 & Streptomyces spiralis NBRC $14215^{\mathrm{T}}$ & AB184575 & 99.87 \\
\hline ZNW001 & S. bungoensis DSM $41781^{\mathrm{T}}$ & KQ948892 & 99.49 \\
\hline YNW004 & S. morookaense LMG $20074^{\mathrm{T}}$ & AJ781349 & 99.74 \\
\hline TNW007 & S. coelicoflavus NBRC $15399^{\mathrm{T}}$ & AB184650 & 99.62 \\
\hline KHS006 & S. bungoensis DSM $41781^{\mathrm{T}}$ & KQ948892 & 99.74 \\
\hline FHS015 & S. albaduncus JCM $4715^{\mathrm{T}}$ & AY999757 & 100.00 \\
\hline YNS007 & Streptomyces chattanoogensis NRRL ISP-5002 ${ }^{\mathrm{T}}$ & LGKG01000206 & 99.25 \\
\hline WHS020 & Streptomyces omiyaensis NBRC $13449^{\mathrm{T}}$ & AB184411 & 99.87 \\
\hline KNS006 & N. nova NBRC $15556^{\mathrm{T}}$ & BDBN01000167 & 100.00 \\
\hline SNS004 & S. hyaluromycini $\mathrm{NBRC} 110483^{\mathrm{T}}$ & BCFL01000051 & 98.86 \\
\hline
\end{tabular}




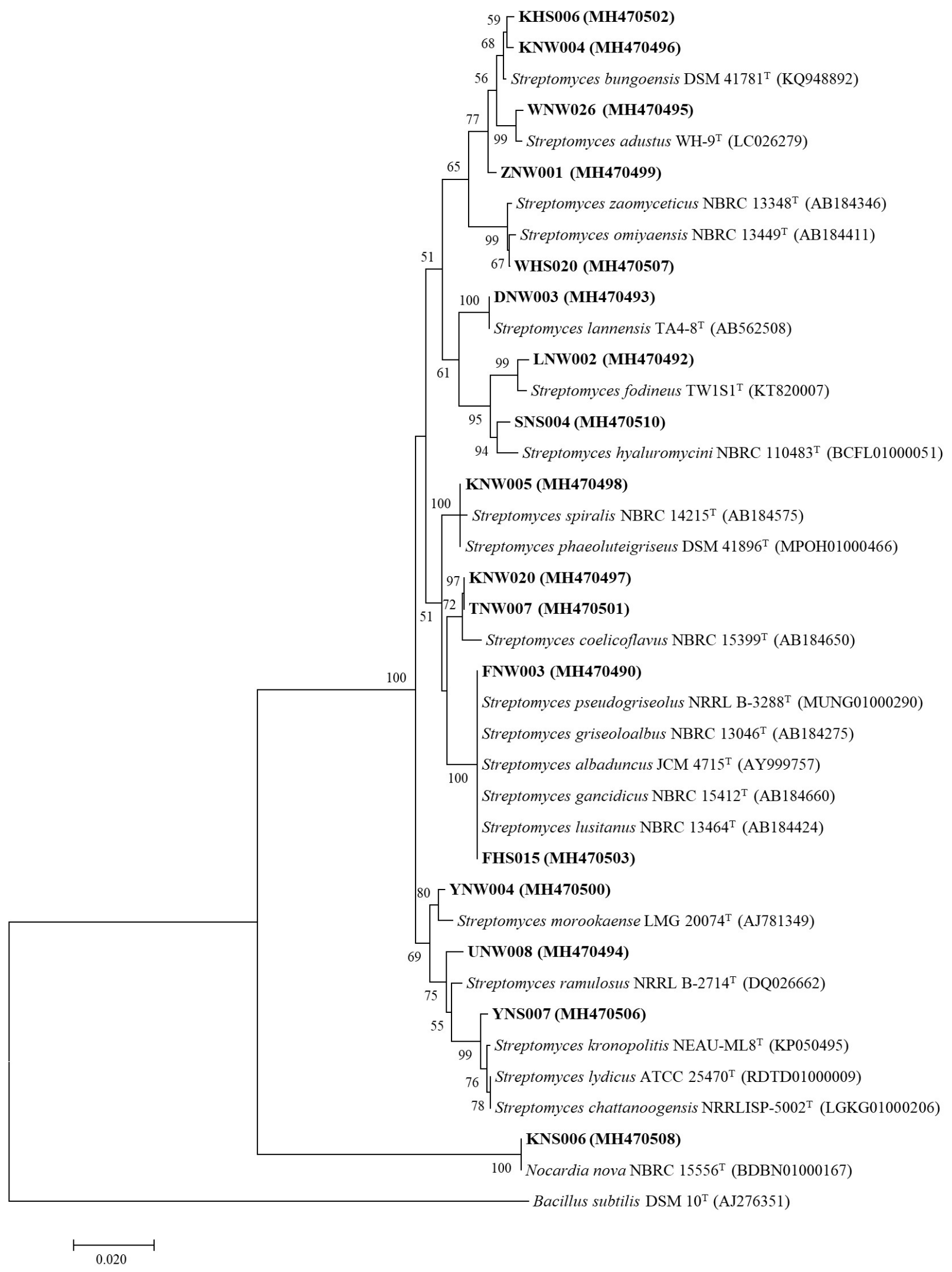

Figure 2. Neighbor-joining tree of the $16 \mathrm{~S}$ rRNA gene sequences inferred the phylogenetic relationships between the isolated strains with other members of Actinobacteria. Bootstrap values calculated from 1,000 resamples with values over $50 \%$ were shown at the respective node. Bar 0.02 nucleotide substitutions per site. 
Table 4. Tolerance test against acidic or $0.3 \%$ bile salt in ISP2 broth for 2 -hours incubation of Streptomyces sp.

\begin{tabular}{lccccccc}
\hline Strains & pH 2 & pH 3 & pH 4 & pH 5 & pH 6 & pH 7 & 0.3\% bile salt \\
\hline YNW004 & ++ & ++ & ++ & ++ & +++ & +++ & +++ \\
SHS004 & - & - & + & + & + & + & + \\
LNW002 & ++ & +++ & +++ & +++ & +++ & +++ & +++ \\
ZNW001 & - & - & + & ++ & ++ & ++ & ++ \\
TNW007 & - & - & - & ++ & ++ & ++ & ++ \\
\hline
\end{tabular}

The level of tolerance was evaluated by counting the observed actinomycete colonies; $1-100$ colonies represent,$+ 2-200$ colonies represent ++ , and more than 200 colonies represent +++ , while none of the colony represent - .

related strains are required to verify the identification of new species. Previous studies indicated the production of bioactive compounds from some predicted strains. For examples, both FNW003 and FSH015, which inhibited all tested bacteria with large inhibition zone $(>10 \mathrm{~mm}$ ) (Table 2$)$, were closely related to $S$. albaduncas which was reported to produce daunomycin with high anti-Gram-positive bacterial activity (Tsukiura et al., 1964).

\section{Acid and bile salt tolerance test}

After rechecking the antibacterial activity, five streptomyces isolates with consistent and potent activity (YNW004, SHS004, LNW002, ZNW001, and TNW007) were tested for acid and bile salt tolerance test, and the results are summarized in Table 4. LNW002 and YNW004 were tolerated in the liquid cultivation with ISP2 at the variety of acidic $\mathrm{pH}$ from $\mathrm{pH} 2$ to 7 at 2 hours. Moreover, it could tolerate the presence of $0.3 \%$ bile salt, whereas the others could grow up since $\mathrm{pH}$ 4. From the literature, most Actinobacteria are mesophilic and grow in soils with a neutral $\mathrm{pH}$, and they grow in the $\mathrm{pH}$ range from 6 to 9 (Barka et al., 2016), such that Streptomyces sp. MUM212, isolated from mangrove forests, could grow between $\mathrm{pH} 4$ and 7 (Tan et al., 2017). In this study, the microorganisms were isolated from the acidic agricultural soil (Table 1), which lead to the excellent tolerance to acidity (Hagedorn, 1976). Isolates LNW002 and YNW004 were identified as Streptomyces fodineus $\mathrm{TW}^{\mathrm{SS}} 1^{\mathrm{T}}$ (KT820007) and Streptomyces morookaense LMG 20074 ${ }^{\mathrm{T}}$ (AJ781349) with similarity at $99.60 \%$ and $99.74 \%$, respectively (Table 3). S. fodineus $\mathrm{TW}_{\mathrm{S} 1}{ }^{\mathrm{T}}$ was identified as the Actinobacterium with antifungal activity isolated from a mine area soil in Korea (Kim et al., 2019). Its growth occurred at $\mathrm{pH} 4-9$ and in the presence of up to $8 \%(w / v) \mathrm{NaCl}$.

Probiotics are one of the alternative methods to control the pathogenic bacterial growth in aquaculture (Wang et al., 2019). Most of the common probiotic bacteria are lactic acid bacteria, and Bacillus (de Vrese and Schrezenmeir, 2008) ,and Bacillus sp. has been used in the animals because of their ability to produce antimicrobial compounds with excellent resistance to the gastric juice due to the endospore formation (Papadimitriou et al., 2015). In the case of streptomycetes, their practical application as probiotics in aquaculture was scarcely studied despite their potential to produce a variety of bioactive compounds. Not only antibiotics, but streptomycetes also represent the antibacterial activity via siderophore production (Yang et al., 2019) and the bacteriocin production (Farris et al., 2011). In a previous research, Das et al. (2010) conveyed the beneficial effects of streptomycetes-supplemented feed on black tiger shrimp, Penaeus monodon, with improved length, wet weight, and survival rate with/without the challenge of Vibrio harveyi. Another study by
Babu et al. (2018) pointed out that granulated streptomycetes could treat the pollutant in Penaeus monodon rearing system. Moreover, Bernal et al. (2017) suggested that some Streptomyces strains alone or in combination with Bacillus, exerted probiotic properties through improving growth, modulating the immune response, adjusting host and water microbiota, and increasing disease resistance on white shrimp Litopenaeus vannamei. Recently, from microbiome analysis, the Actinobacteria were identified in the gut of Nile tilapia (Hallali et al., 2018), which indicated the possibility of using actinomycetes for probiotics. Since Streptomyces sp. LNW002 and YNW004 possess vigorous antibacterial activity against the bacterial pathogens in Nile tilapia and tolerate the acidic $\mathrm{pH} 2$ and bile salt up to $0.3 \%$, further study on other probiotic properties, e.g., adherence to the intestinal epithelium, exoenzyme production, as well as the host immunostimulant, is promising (Kaktcham et al., 2018; Markowiak and Śliżewska, 2018).

\section{CONCLUSION}

Bacterial infection in Nile tilapia causes a significant economic loss in Thailand and other countries. One of the possible preventive methodologies is to apply probiotics in the gut of Nile tilapia to enhance animal nutrition, immune response, and productivity. From this study, Streptomyces strains LNW002 and YNW004 proved to be potentially effective against bacterial pathogens in Nile tilapia. They also tolerated the mimic condition in the gut and small intestine of Nile tilapia. The experiments highlight the actinomycetes as alternative microorganisms to be developed as probiotics for an eco-friendly and sustainable aquaculture.

\section{ACKNOWLEDGMENTS}

This work was financially supported by a scholarship from the Faculty of Science, King Mongkut's University of Technology Thonburi (SCI 60-001). The authors thank Associate Professor Triwit Rattanarojpong, from the Department of Microbiology, Faculty of Science, King's Mongkut University of Technology Thonburi, Thailand, and Dr. Saengchan Senapin, from the Fish Health Platform, Center of Excellence for Shrimp Molecular Biology and Biotechnology (Centex Shrimp), Faculty of Science, Mahidol University, Bangkok, Thailand, for providing the four tested bacterial strains, and Dr. Daniel Montefusco for proofreading the manuscript.

\section{CONFLICT OF INTEREST}

There are no conflicts of interest. 


\section{FUNDING}

None.

\section{REFERENCES}

Babu DT, Archana K, Kachiprath B, Solomon S, Jayanath G, Singh, ISB, Philip R. Marine actinomycetes as bioremediators in Penaeus monodon rearing system. Fish Shellfish Immunol, 2018; 75:231-42.

Balouiri M, Sadiki M, Ibnsouda SK. Methods for in vitro evaluating antimicrobial activity: a review. J Pharm Anal, 2016; 6:71-9.

Barka EA, Vatsa P, Sanchez L, Gaveau-Vaillant N, Jacquard C, Klenk HP, Clement C, Ouhdouch Y, van Wezel GP. Taxonomy, physiology, and natural products of actinobacteria. Microbiol Mol Biol Rev, 2016; 80:1-43.

Bérdy J. Thoughts and facts about antibiotics: where we are now and where we are heading? J Ant, 2012; 65:385-95.

Bernal MG, Marrero RM, Campa-Córdova ÁI, Mazón-Suástegui, JM. Probiotic effect of Streptomyces strains alone or in combination with Bacillus and Lactobacillus in juveniles of the white shrimp Litopenaeus vannamei. Aquac Int, 2017; 25:927-39.

Bhatti AA, Haq S, Bhat RA. Actinomycetes benefaction role in soil and plant health. Microb Pathog, 2017; 111:458-67.

Chen J, Wang B, Lu Y, Guo Y, Sun J, Wei B, Zhang H, Wang H. Quorum sensing inhibitors from marine microorganisms and their synthetic derivatives. Mar Drugs, 2019; 17:80.

Das S, Ward LR, Burke C. Prospects of using marine actinobacteria as probiotics in aquaculture. Appl Microbiol Biotechnol, 2008; 81:419-29.

Das S, Ward LR, Burke C. Screening of marine Streptomyces spp. for potential use as probiotics in aquaculture. Aquaculture, 2010; 305:32-41.

de Vrese M, Schrezenmeir J. Probiotics, prebiotics, and synbiotics. In: Stahl U, Donalies UEB, Nevoigt E, (ed.). Food biotechnology. Advances in biochemical engineering/biotechnology. Springer, Berlin, Heidelberg, pp 1-66, 2008.

Dong HT, Nguyen VV, Le HD, Sangsuriya P, Jitrakorn S, Saksmerprome V, Senapin S, Rodkhum C. Naturally concurrent infections of bacterial and viral pathogens in disease outbreaks in cultured Nile tilapia (Oreochromis niloticus) farms. Aquaculture, 2015; 448:427-35.

Donkor ES, Anim-Baidoo I, Fei E, Amponsah C, Olu-Taiwo M, Nana-Adjei D, Owusu E, Forson AO. Occurrence of antibiotic residues and antibiotic-resistant bacteria in Nile tilapia sold in Accra, Ghana: public health implications. J Food Res, 2018; 7:129-37.

Dung TT, Haesebrouck F, Tuan NA, Sorgeloos P, Baele M, Decostere A. Antimicrobial susceptibility pattern of Edwardsiella ictaluri isolates from natural outbreaks of bacillary necrosis of Pangasianodon hypophthalmus in Vietnam. Microb Drug Resist, 2008; 14:311-6.

Edgar RC. MUSCLE: multiple sequence alignment with high accuracy and high throughput. Nucleic Acids Res, 2004; 32:1792-7.

Euanorasetr J, Intra B, Mongkol P, Chankhamhaengdecha S, Tuchinda P, Mori M, Shiomi K, Nihira T, Panbangred W. Spirotetronate antibiotics with anti-Clostridium activity from Actinomadura sp. 2EPS. World J Microbiol Biotechnol, 2015; 31:391-8.

Euanorasetr J, Nilvongse A, Tantimavanich S, Nihira T, Igarashi $\mathrm{Y}$, Panbangred W. Identification and characterization of soil-isolated Streptomyces SJE177 producing actinomycin. Southeast Asian J Trop Med Public Health, 2010; 41:1177-87.

Farris MH, Duffy C, Findlay RH, Olson JB. Streptomyces scopuliridis sp. nov., a bacteriocin-producing soil streptomycete. Int J Syst Evol Microbiol, 2011; 61:2112-6.

Goodfellow M. Phylum XXVI. Actinobacteria phyl. nov. In: Whitman W, Goodfellow M, Kämpfer P, Busse HJ, Trujillo M, Ludwig W, Suzuki KI, Parte A. (eds.). Bergey's manual of systematic bacteriology. Springer, New York, NY, pp 33-2028, 2012.

Goodfellow M, Williams ST. Ecology of actinomycetes. Annu Rev Microbiol, 1983; 37:189-216.
Hagedorn C. Influences of soil acidity on Streptomyces populations inhabiting forest soils. Appl Environ Microbiol, 1976; 32:36875

Hallali E, Kokou F, Chourasia TK, Nitzan T, Con P, Harpaz S, Mizrahi I, Cnaani A. Dietary salt levels affect digestibility, intestinal gene expression, and the microbiome, in Nile tilapia (Oreochromis niloticus). PLoS One, 2018; 13:e0202351.

Hayakawa M. Studies on the isolation and distribution of rare actinomycetes in soil. Actinomycetologica, 2008; 22:12-9.

Hendershot WH, Lalande H, Duquette M. Soil reaction and exchangeable acidity. In: Carter MR, Gregorich EG (eds.). Soil sampling and methods of analysis. CRC Press, Taylor \& Francis Group, Boca Raton, FL, pp 173-8, 2008.

Intra B, Mungsuntisuk I, Nihira T, Igarashi Y, Panbangred W. Identification of actinomycetes from plant rhizospheric soils with inhibitory activity against Colletotrichum spp., the causative agent of anthracnose disease. BMC Res Notes, 2011; 4:98.

Kaktcham PM, Temgoua JB, Zambou FN, Diaz-Ruiz G, Wacher C, Pérez-Chabela ML. In vitro evaluation of the probiotic and safety properties of bacteriocinogenic and non-bacteriocinogenic lactic acid bacteria from the intestines of Nile Tilapia and common carp for their use as probiotics in aquaculture. Probiotics Antimicrob Proteins, 2018; 10:98-109.

Kannika K, Pisuttharachai D, Srisapoome P, Wongtavatchai J, Kondo H, Hirono I, Unajak S, Areechon N. Molecular serotyping, virulence gene profiling and pathogenicity of Streptococcus agalactiae isolated from tilapia farms in Thailand by multiplex PCR. J Appl Microbiol, 2017; 122:1497-507.

Kieser T, Bibb MJ, Buttner MJ, Chater KF, Hopwood DA. Practical Streptomyces genetics. The John Innes Foundation, Norwich, UK, 2000.

Kim MK, Kang HJ, Roh SG, Park JS, Kim SB. Streptomyces fodineus sp. nov., an actinobacterium with antifungal activity isolated from mine area soil. Int J Syst Evol Microbiol, 2019; 69:1350-4.

Kumar V, Marin-Navarro J, Shukla P. Thermostable microbial xylanases for pulp and paper industries: trends, applications and further perspectives. World J Microbiol Biotechnol, 2016; 32:34.

Markowiak P, Śliżewska K. The role of probiotics, prebiotics and synbiotics in animal nutrition. Gut Pathog, 2018; 10:21.

Ministry of Agriculture and Cooperatives (Thailand). Statistics of freshwater aquaculture production 2014. Department of Fisheries, Ministry of Agriculture and Cooperatives, Bangkok, Thailand, 2016.

Okocha RC, Olatoye IO, Adedeji OB. Food safety impacts of antimicrobial use and their residues in aquaculture. Public Health Rev, 2018; 39:21.

Papadimitriou K, Zoumpopoulou G, Foligné B, Alexandraki V, Kazou M, Pot B, Tsakalidou E. Discovering probiotic microorganisms: In vitro, in vivo, genetic and omics approaches. Front Microbiol, 2015; 6:58.

Saini A, Aggarwal NK, Sharma A, Yadav A. Actinomycetes: a source of lignocellulolytic enzymes. Enzyme Res, 2015; 2015:15.

Saitou N, Masatoshi N. The neighbor-joining method: a new method for reconstructing phylogenetic trees. Mol Biol Evol, 1987; 4:40625

Ser HL, Tan LTH, Law JWF, Chan KG, Duangjai A, Saokaew S, Pusparajah P, Ab Mutalib NS, Khan TM, Goh BH, Lee LH. Focused review: cytotoxic and antioxidant potentials of mangrove-derived Streptomyces. Front Microbiol, 2017; 8:2065.

Shirling EB, Gottlieb D. Methods for characterization of Streptomyces species. Int J Syst Evol Microbiol, 1966; 16:313-40.

Shivlata L, Satyanarayana T. Thermophilic and alkaliphilic actinobacteria: biology and potential applications. Front Microbiol, 2015; $6: 1014$.

Sripreechasak P, Phongsopitanun W, Tamura T, Tanasupawat S. Streptomyces krungchingensis sp. nov., isolated from soil. Int J Syst Evol Microbiol, 2017; 67:50-4.

Standards Association of Australia. Determination of the moisture content of soil - oven drying method (standard method). In: 
Methods of testing soils for engineering purposes, part B - Soil moisture content tests. N.S.W. : The Association, North Sydney, Australia, 1977.

Tajima K, Takahashi Y, Seino A, Iwai Y, Omura S. Description of two novel species of the genus Kitasatospora Omura et al. 1982, Kitasatospora cineracea sp. nov. and Kitasatospora niigatensis sp. nov. Int J Syst Evol Microbiol, 2001; 51:1765-71.

Tan LTH, Chan KG, Khan TM, Bukhari SI, Saokaew S, Duangjai A, Pusparajah P, Lee LH, Goh BH. Streptomyces sp. MUM212 as a source of antioxidants with radical scavenging and metal chelating properties. Front Pharmacol, 2017; 8:276.

Tan LTH, Chan KG, Lee LH, Goh BH. Streptomyces bacteria as potential probiotics in aquaculture. Front Microbiol, 2016; 7:1-8.

Thakur D, Yadav A, Gogoi BK, Bora TC. Isolation and screening of Streptomyces in soil of protected forest areas from the states of Assam and Tripura, India, for antimicrobial metabolites. J Mycol Med, 2007; 17:242-9.

Tsukiura H, Okanishi M, Ohmori T, Koshiyama H, Miyaki T, Kitazima H, Kawaguchi H. Danomycin, a new antibiotic. J Antibiot, 1964; $17: 39-47$

Waltman WD, Shotts EB. Antimicrobial susceptibility of Edwardsiella ictaluri. J Wildl Dis, 1986; 22:173-7.

Wang A, Ran C, Wang Y, Zhang Z, Ding Q, Yang Y, Olsen RE, Ringø E, Bindelle J, Zhou Z. Use of probiotics in aquaculture of China-A review of the past decade. Fish Shellfish Immunol, 2019; 86:734-55.

Wang M, Lu M. Tilapia polyculture: a global review. Aquac Res, 2016; 47:2363-74.
Win S, Taveesak J, Nutthawan N, Puntanat T, Kwanrawee S, Alongkorn A. Outbreaks of Tilapia lake virus infection, Thailand, 20152016. Emerg Infect Dis, 2017; 23:1031.

Yang M, Zhang J, Liang Q, Pan G, Zhao J, Cui M, Zhao X, Zhang Q, Xu D. Antagonistic activity of marine Streptomyces sp. S073 on pathogenic Vibrio parahaemolyticus. Fish Sci, 2019; 85:533-43.

Yoon SH, Ha SM, Kwon S, Lim J, Kim Y, Seo H, Chun J. Introducing EzBioCloud: a taxonomically united database of $16 \mathrm{~S}$ rRNA gene sequences and whole-genome assemblies. Int J Syst Evol Microbiol, 2017; 67:1613-7.

Zhang Z, Lan J, Li Y, Hu M, Yu A, Zhang J, Wei S. The pathogenic and antimicrobial characteristics of an emerging Streptococcus agalactiae serotype IX in Tilapia. Microb Pathog, 2018; 122:39-45.

How to cite this article:

Euanorasetr J, Chotboonprasit V, Ngoennamchok W, Thongprathueang S, Promprateep A, Taweesaga S, Chatsangjareon $\mathrm{P}$, Intra $\mathrm{B}$. Isolation and characterization of aerobic actinomycetes with probiotic properties in Nile tilapia. J Appl Pharm Sci, 2020; 10(09):040-049. 